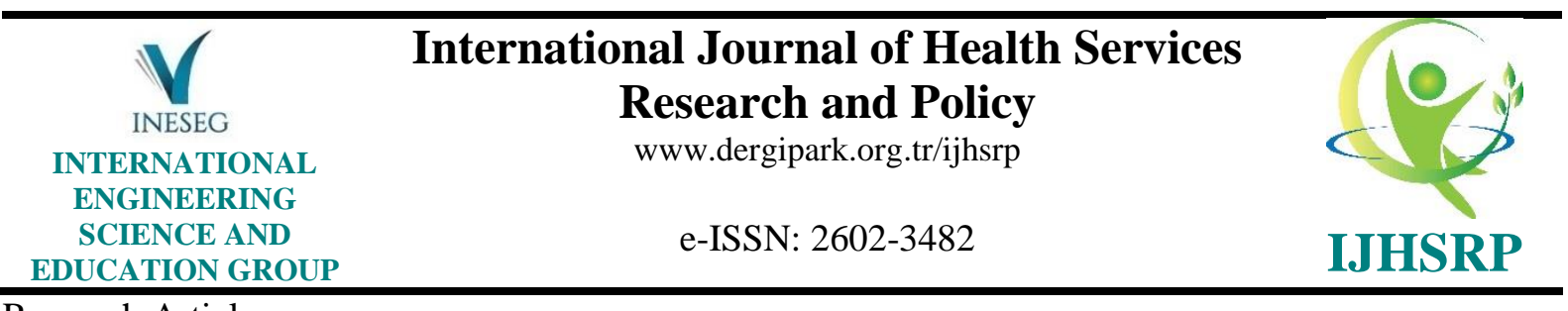

Research Article

\title{
APPLICATION AND BELIEF OF BREAST SELF-EXAMINATION (BSE) IN BREAST CANCER IN FEMALE STUDENTS IN SCIENCE AND SOCIAL SCIENCES: THE CASE OF TURKEY
}

\author{
Seda SÖGÜT*1 Eda CANGÖL $L^{2}$ \\ ${ }^{1}$ Çanakkale Onsekiz Mart University, Faculty of Health Sciences, Department of Midwifery, Çanakkale, Turkey \\ ${ }^{2}$ Çanakkale Onsekiz Mart University, Faculty of Health Sciences, Department of Midwifery, Çanakkale, Turkey \\ *Corresponding author: sdengl@ hotmail.com
}

\begin{abstract}
In Turkey, breast cancer is the most common type of cancer among women with a rate of 25\%. Early diagnosis of breast cancer facilitates treatment and prolongs patient life. BSE, which is performed at regular intervals, is a simple and economic method that protects the privacy of women in the early diagnosis of breast cancer. The objective of this study was to investigate the application and belief of BSE in breast cancer in women studying outside the health field. Descriptive research was used to investigate the application and belief of BSE in breast cancer in 600 women studying in the fields of science and social sciences of a university. Descriptive characteristics, breast cancer, and breast selfexamination were used to collect data, and the Champion Health Belief Model Scale (CHBMS) was also used. The difference between the mean CSIMS scores of the students with and without BSE was evaluated statistically. It was found that $15.2 \%(n=91)$ of the students applied BSE regularly every month. $17.5 \%$ of the participants indicated that breast cancer may not have a symptom. In the early diagnosis of breast cancer, 54\% of the participants indicated that they performed BSE. Moreover, $49.8 \%$ of the participants noted that they did not get any information about BSE before. The total scale means difference $(P=0.007)$ between the participants who applied and did not apply BSE was statistically significant. It was concluded that the female students studying in science and social sciences had insufficient knowledge about breast cancer and BSE, early diagnosis, symptoms, and physician examination. Peer education programs are recommended.
\end{abstract}

Keywords: Student, breast cancer, breast self-examination (BSE), health, beliefs.

Received: August 13, $2020 \quad$ Accepted: November 2, 2020

\section{Introduction}

Cancer is one of the leading causes of death for women. Cancer ranks second among the causes of death in our country and in the world. Breast cancer is a major global problem [1]. It affects 2.1 million women each year, causing the highest number of cancer-related deaths among women. According to the World Health Organisation (WHO), 627,000 women are estimated to have died of breast cancer in 2018 [2]. Approximately one in 6 deaths globally and one in every 5 deaths in our country are caused by cancer. In the last year, 17,531 women were diagnosed with breast cancer. It can 
be seen that one in every four women has breast cancer [3]. In this context, breast cancer rates show a global increase. However, breast cancer is a widespread type of cancer that usually shows a slow development rate, and it is possible to achieve successful treatment results in early diagnosis. Early diagnosis and treatment of breast cancer in women may be effective in the protection and promotion of health and in terms of decreasing mortality, improving quality of life, and preventing physical pain and psychosocial problems $[4,5,6]$.

"Breast Self-Examination" (BSE), "Clinical Breast Examination" (CBE), and "Mammography" (MG) are the three recommended and complementary methods for early diagnosis of breast cancer. BSE should be performed once a month from the age of 20 on the fifth and seventh day of menstruation, and the same day of every month after menopause. The American Cancer Society (ACS) recommends annual BSE for women from the age of 20, CBE every three years between the ages of 20 and 40, and $\mathrm{CBE}$ and $\mathrm{MG}$ from the age of 40 without seeking clinical findings.

BSE is simple to apply, does not require special tools, and does not cost much. It is suggested that BSE should be made for the early recognition and awareness of possible changes by recognizing breast tissue. In previous studies, health beliefs are reported to be the most important factor affecting breast cancer screenings $[10,11,12,13]$. In order for BSE to be implemented for the early diagnosis of cancer, effective education programs that will increase awareness in the target audience should be spread and healthy behaviours should be promoted. BSE ensures that women participate in health care by taking responsibility for their own health and increase their awareness and awareness of their own body.

The Health Belief Model is the most commonly used model to increase the early diagnosis behaviours of breast cancer. The key concepts of the model suggest that health behaviour will occur if individuals believe in the results about the severity of the disease, are aware of the benefits of screening, perceive the disease as a vulnerability for themselves, and are aware of the obstacles to behaviour. If the individual's perception of sensitivity to the disease is high and the perception of disability is low, the probability of carrying out the proposed health-related activities will increase [14].

Health personnel has important roles and responsibilities in terms of acquiring the habit with BSE and in the process of preventing breast cancer. Students are expected to develop their knowledge and skills on BSE from the time they start undergraduate education. Studies on beliefs and application regarding breast cancer and breast self-examination in women show that it is not sufficient for early diagnosis $[12,15,16]$.

Early diagnosis and screening programs are unlikely to be successful unless the importance of early diagnosis is recognized by society. In particular, the awareness and consciousness of women who are studying outside the health field are important in terms of decreasing mortality and protecting and improving health. In light of this information, this study was conducted to investigate the application and belief of BSE in breast cancer in women studying outside the health field.

\section{Material and Methods}

\subsection{Study design and setting}

This research is of descriptive type. 


\subsection{Population and Sample of the Study}

The population of the study was composed of 750 students studying in the science and social departments of a University. Without sample selection from the population, the study was completed with 600 students who were voluntary to participate in the study. The participation rate for the study was determined as $80 \%$.

\subsection{Data Collection Tools}

The data of the study was collected through the "Question form" and "Champion Health Belief Model Scale" (CHBMS) prepared by scanning the literature.

Question form: The form developed by the researchers is a 19-item form designed to determine age, educational status, income status, health insurance, presence of breast cancer in families and friends, and BSE application status and frequency.

Champion's Health Belief Model Scale: It is based on the Health Belief Model in Nursing. In 1984, Victoria Champion developed the Health Belief Model Scale for breast cancer screening [17]. In Turkey, it was adapted by Gözüm \& Aydin (2004) and Karayurt \& Dramalı (2007). In this study, the form adapted to Turkish by Karayurt \& Dramali (2007) was used [18,19]. The scale is a 42-item, 5-likert type, and six-dimension form that includes the six concepts of the Health Belief Model. The subdimension of sensitivity perception related to breast cancer consists of three items and expresses the perceived personal risks of breast cancer. The sub-dimension of the perception of seriousness related to breast cancer is composed of seven items and defines the degree of the individual threat perceived from breast cancer. The sub-dimension of benefit perception related to BSE implementation consists of four items and expresses the perceived advantages of BSE. The sub-dimension of obstacle perception related to BSE implementation consists of 11 items and defines the perceived barriers related to BSE. The confidence sub-dimension of BSE application consists of 10 items and expresses the perceived individual competence in BSE application skills in order to detect abnormal breast masses. The subdimension of health motivation consists of seven items and expresses interests and concerns about the health status of individuals.

\subsection{Application of the Study}

Data collection tools were applied to the students included in the study through face to face interview method for 20-25 minutes.

\subsection{Inclusion Criteria}

- Being a student studying in science and social departments of a university

- Volunteering to participate in the research

\subsection{The Exclusion Criteria of the Study}

-Declining to participate in the study.

\subsection{Ethical Approval}

Permission was obtained from the Ethics Committee of Uşak University (Code of Ethics: 97627247-050.99-8887) on March 10, 2016, to conduct the study. Necessary permissions were obtained from the institutions. Before starting the data collection process, the students were informed about the 
purpose and scope of the research and their verbal and written consents about the fact that they agreed to participate in the research were obtained.

\subsection{Data Assessment}

The statistical analysis of the study was performed using the SPSS 23.0 (SPSS Inc. Chicago, IL) program. Number (n), percentage, mean, and standard deviation were used to evaluate the descriptive characteristics. In the comparison of the scores of the sub-dimensions of the scale and the scale between the two groups, the Independent Sample T-test (Independent T-test) was used for parametric subdimensions, whereas Mann Whitney U test was used for non-parametric sub-dimensions. Chi-square test was used to compare categorical variables. Statistical significance was accepted as $\mathrm{P}<0.05$.

\section{Results}

The study was conducted with 600 young women. The mean age of the participants was $21.54 \pm 1.37(\mathrm{n}=600)$. It was determined that $18.17 \%$ of the participants were studying in sciencerelated departments and $81.83 \%$ were studying in social-related departments. When the participants were evaluated in terms of income and expenses, it was found that $24.0 \%$ of the income was less than the expenses, that $66.2 \%$ of the income and expenses were equal, and that $9.8 \%$ of the income was less than the expenses. $87.7 \%$ had health insurance. It was determined that the rate of those who made BSE was $15.17 \%$ and that those with breast cancer in their relatives were $14.8 \%$. It was determined that there was a statistically significant relationship between BSE and those who had breast cancer in their relatives $(\mathrm{P}=0.001)$. Smoking and alcohol use rates were determined as $25 \%$ and $10 \%$, respectively. There was a statistically significant relationship between alcohol and smoking $(\mathrm{P}=0.000)$. There was no statistically significant difference between BSE and smoking and alcohol use $(\mathrm{P}=0.324$ and $\mathrm{P}=0.122$, respectively) (Table 1).

Table 1. Distribution of socio-demographic characteristics of participants

\begin{tabular}{ccc}
\hline Characteristics & N & \% \\
\hline Age & & \\
$\mathbf{2 0 - 2 4}$ & 579 & 96.5 \\
$\mathbf{2 5 - 2 8}$ & 21 & 3.5 \\
\hline University Departments & & \\
Science & 109 & 18.17 \\
Social & 491 & 81.83 \\
\hline Income level & & \\
Low & 144 & 24.0 \\
Middle & 397 & 66.2 \\
High & 59 & 9.8 \\
\hline Health assurance & & \\
Yes & 526 & 87.7 \\
No & 74 & 12.3 \\
\hline
\end{tabular}


Table 1 continued

\begin{tabular}{lcc}
\hline $\begin{array}{c}\text { Breast Self-Examination } \\
\text { Yes }\end{array}$ & $\mathbf{9 1}$ & \\
No & $\mathbf{5 0 9}$ & $\mathbf{1 5 . 1 7}$ \\
\hline $\begin{array}{l}\text { Family History of } \quad \text { breast } \\
\text { cancer? }\end{array}$ & 89 & $\mathbf{8 4 . 8 3}$ \\
Yes & 511 & 14.8 \\
No & & 85.2 \\
\hline $\begin{array}{l}\text { Do you use to smoke? } \\
\text { Yes }\end{array}$ & 150 & \\
No & 450 & 25.0 \\
\hline Do you use alcohol? & & 75.0 \\
Yes & 60 & 10.0 \\
No & 540 & 90.0 \\
\hline
\end{tabular}

The participants were asked for various information about breast cancer. It was determined that $96.7 \%$ of the participants had no problem with breast before and that $6.3 \%$ made breast examination in the last year. It was also determined that there was a statistically significant difference between those who had a previous breast problem and those who had breast examinations in the last year $(\mathrm{P}=0.000)$. While $17.5 \%$ of the participants stated that there would be no symptoms in breast cancer, $79.0 \%$ of the participants stated that there may be swelling in the breast. $66.8 \%$ of the participants said that there might be a pain in the breast, while 58.5\% said that there may be swelling in the armpit and $34.5 \%$ said that there may be bloody discharge in the breast. $31.5 \%$ reported that there may be a deformity in the breast, whereas $29.5 \%$ stated that there may be a wound in the breast and $28.0 \%$ reported that there may be yellow-white discharge in the breast. $26.8 \%$ of the participants stated that there may be breast withdrawal. While $54 \%$ of the participants stated that breast cancer could be determined by BSE, $47.7 \%$ stated that breast cancer could be detected by mammography and $44.2 \%$ stated that breast cancer could be determined by gynecologist evaluation. While $21.3 \%$ of the participants stated that breast cancer could be determined by the evaluation made by the general surgeon, $9 \%$ stated that they did not know about this issue and $2 \%$ stated that it could not be determined. $61.2 \%$ of the participants stated that regular controls should be conducted from the age of 20 , whereas $15.8 \%$ reported that they should be done from the age of $30.38 .0 \%$ of the participants stated that the frequency of mammography should be at least once every six months, while $34.0 \%$ stated that the frequency of mammography should be once a year. $44.8 \%$ of the participants who had a cancer history stated that they would not want surgical treatment whereas $39.2 \%$ stated that only one part of the breast should be removed. $50.2 \%$ of the participants stated that they received information about BSE. The participants reported that they received information about BSE in different ways such as health personnel $(16.7 \%$,) TV/radio/newspaper, etc. $(9.0 \%$,) internet $(7.3 \%)$, and other places $(7.2 \%$.) $13.3 \%$ of the participants reported that they received information about mammography from a doctor/nurse. It was found that there was a statistically significant difference between the participants' information about BSE and the obtained information about mammography $(\mathrm{P}=0.000)$ (Table 2$)$. 
Table 2. Information of participants about breast cancer

\begin{tabular}{|c|c|c|}
\hline & $\mathrm{N}$ & $\%$ \\
\hline \multicolumn{3}{|l|}{$\begin{array}{l}\text { Have you ever had a health } \\
\text { problem with your breast (such } \\
\text { as breast cancer)? }\end{array}$} \\
\hline Yes & 20 & 3.3 \\
\hline No & 580 & 96.7 \\
\hline \multicolumn{3}{|l|}{$\begin{array}{l}\text { Did you have a doctor's checkup } \\
\text { for a breast exam in the last }\end{array}$} \\
\hline Yes & $\begin{array}{c}58 \\
562\end{array}$ & $\begin{array}{l}0.5 \\
93.7\end{array}$ \\
\hline & & \\
\hline \multicolumn{3}{|l|}{$\begin{array}{l}\text { What do you think are the } \\
\text { symptoms of breast cancer? }\end{array}$} \\
\hline Pain in the breast & 401 & 66.8 \\
\hline Swelling from the breast & 474 & 79.0 \\
\hline $\begin{array}{l}\text { Swelling from hand under the } \\
\text { armpit }\end{array}$ & 351 & 58.5 \\
\hline Retraction of breast & 161 & 26.8 \\
\hline Bloody discharge from the nipple & 207 & 34.5 \\
\hline Yellow-white flow from the & 168 & 28.0 \\
\hline nipple & 189 & 31.5 \\
\hline Deformity of a single breast & 177 & 29.5 \\
\hline \multicolumn{3}{|l|}{ Scare on breast } \\
\hline \multicolumn{3}{|l|}{$\begin{array}{l}\text { Which of the following should be } \\
\text { done to detect breast cancer } \\
\text { early? }\end{array}$} \\
\hline Self-examination & 324 & 54.0 \\
\hline Mammography & 286 & 47.7 \\
\hline Gynecologist breast examination & 265 & 44.2 \\
\hline $\begin{array}{l}\text { General surgery specialist should } \\
\text { examine }\end{array}$ & 128 & 21.3 \\
\hline I do not know & & \\
\hline Breast cancer cannot be detected & 54 & 9.0 \\
\hline early & 12 & 2.0 \\
\hline \multicolumn{3}{|l|}{$\begin{array}{l}\text { At what age do you think regular } \\
\text { breast checks should start? }\end{array}$} \\
\hline 20 & 367 & 61.2 \\
\hline 30 & 95 & 15.8 \\
\hline 35 & 59 & 9.8 \\
\hline 40 and over & 79 & 13.2 \\
\hline \multicolumn{3}{|l|}{$\begin{array}{l}\text { How often do } \begin{array}{c}\text { you } \\
\text { mammography } \\
\text { should }\end{array} \begin{array}{r}\text { be } \\
\text { performed? }\end{array} \text {. }\end{array}$} \\
\hline Every 3 months & 64 & 10.7 \\
\hline Every 6 months & 228 & 38.0 \\
\hline Once a year & 204 & 34.0 \\
\hline Every $2-5$ years & 104 & 17.3 \\
\hline
\end{tabular}


Table 2 Continued

\begin{tabular}{|c|c|c|}
\hline \multicolumn{3}{|l|}{$\begin{array}{l}\text { If you had breast cancer, which } \\
\text { of the following methods would } \\
\text { you choose? }\end{array}$} \\
\hline $\begin{array}{l}\text { I would like to have my entire } \\
\text { sick breast removed }\end{array}$ & 73 & 12.2 \\
\hline $\begin{array}{l}\text { I would like to have both breasts } \\
\text { removed. }\end{array}$ & 23 & 3.8 \\
\hline $\begin{array}{l}\text { I wish only the part of the breast } \\
\text { with cancer was removed. }\end{array}$ & 235 & 39.2 \\
\hline $\begin{array}{lrcc}\text { I would } & \text { not } & \text { want } & \text { surgical } \\
\text { treatment. } & \text { I } & \text { just } & \text { wanted } \\
\text { medication. } & & & \\
\end{array}$ & 269 & 44.8 \\
\hline \multicolumn{3}{|l|}{$\begin{array}{l}\text { Have you ever received } \\
\text { information about breast self- } \\
\text { examination? }\end{array}$} \\
\hline Yes & 301 & 50.2 \\
\hline No & 299 & 49.8 \\
\hline \multicolumn{3}{|l|}{$\begin{array}{l}\text { Where did you learn about } \\
\text { breast self-examination before? }\end{array}$} \\
\hline From health personnel & 100 & 16.7 \\
\hline From the Internet & 44 & 7.3 \\
\hline $\begin{array}{l}\text { TV / radio / newspaper / } \\
\text { magazine and so on. }\end{array}$ & 54 & 9.0 \\
\hline Other & 103 & 17.2 \\
\hline No answers & 299 & 49.8 \\
\hline \multicolumn{3}{|l|}{ 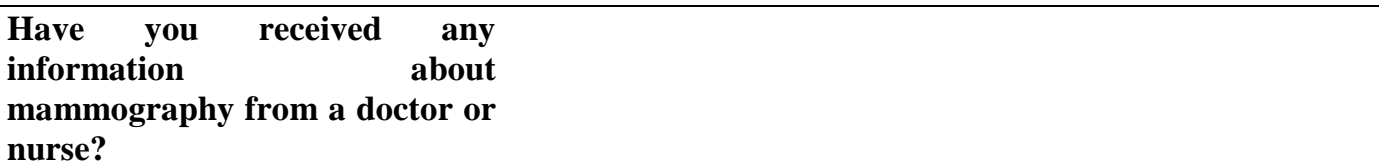 } \\
\hline Yes & 80 & 13.3 \\
\hline No & 520 & 86.7 \\
\hline
\end{tabular}

According to the independent sample test and Mann Whitney $U$ test conducted to determine whether there was a difference between performing BSE and not performing BSE, there was a statistically significant difference between the scale total $(\mathrm{P}=0.007)$, confidence $(\mathrm{P}=0.000)$, health motivation ( $\mathrm{P}$ $=0.000)$ and sensitivity $(\mathrm{P}=0.001)$ and disability $(\mathrm{P}=0.000)$ sub-dimensions. No statistically significant difference was found for the severity $(\mathrm{P}=0.339)$ and benefit $(\mathrm{P}=0.132)$ sub-dimensions compared to the independent sample test. While there was a positive correlation between the scale total and severity $(r=0.601)$, benefit $(r=0.450)$, disability $(r=0.335)$, confidence $(r=0.602)$ and health motivation $(r=0.462)$, sensitivity $(r=0,274)$ sub-dimension was found to be positively correlated with weak strength (Table 3 ). 
Table 3. Statistical evaluation of total scale score and sub-dimensions of participants with and without BSE

\begin{tabular}{|c|c|c|c|c|c|c|}
\hline $\begin{array}{l}\text { Dimension } \\
\text { and Sub- } \\
\text { dimension }\end{array}$ & Group & $\mathbf{N}$ & $\overline{\mathbf{X}}$ & SD & $\mathbf{t} * / \mathbf{u} * *$ & $P$ \\
\hline \multirow[t]{2}{*}{ Scale total } & BSE -Yes & 91 & 132.98 & 14.83 & $2.715 *$ & 0.007 \\
\hline & BSE-No & 509 & 127.98 & 16.39 & & \\
\hline \multirow[t]{2}{*}{ Sensitivity } & BSE -Yes & 91 & 8.34 & 2.63 & $18184.5^{* * *}$ & 0.001 \\
\hline & BSE-No & 509 & 7.51 & 2.25 & & \\
\hline \multirow[t]{2}{*}{ Seriousness } & BSE -Yes & 91 & 22.19 & 5.28 & $-0.956^{*}$ & 0.339 \\
\hline & BSE-No & 509 & 22.77 & 5.35 & & \\
\hline \multirow[t]{2}{*}{ Benefit } & BSE -Yes & 91 & 15.43 & 3.56 & $1.509 *$ & 0.132 \\
\hline & BSE-No & 509 & 14.79 & 3.72 & & \\
\hline \multirow[t]{2}{*}{ Obstacle } & BSE -Yes & 91 & 25.32 & 8.65 & $16376.5^{* * *}$ & 0.000 \\
\hline & BSE-No & 509 & 28.74 & 6.80 & & \\
\hline \multirow[t]{2}{*}{ Confidence } & BSE -Yes & 91 & 35.00 & 6.33 & $6.336^{*}$ & 0.000 \\
\hline & BSE-No & 509 & 29.51 & 7.81 & & \\
\hline Health & BSE -Yes & 91 & 26.70 & 4.28 & $3.858 *$ & 0.000 \\
\hline Motivation & BSE-No & 509 & 24.65 & 4.73 & & \\
\hline
\end{tabular}

*Independent Sample T-Test, **Mann Whitney U Test

\section{Discussion}

In Turkey, the most common type of cancer in women is breast cancer with a rate of $25 \%$. In the early diagnosis of breast cancer, mammography, clinical breast examination, and breast selfexamination (BSE) is recommended. BSE performed regularly and accurately is a simple and economic method that protects the privacy of women [20].

In the prevention of cancer, it is very important to determine the beliefs and application status of women about breast cancer and BSE. It is estimated that the incidence of breast cancer will increase in the coming years due to predisposing factors such as prolonged life expectancy, increased stressors and obesity, and progression of the first gestational age [21]. In particular, informing young adults studying outside the health field about stressors and prevention will facilitate early diagnosis. The aim of this study was to determine the application and belief of BSE in breast cancer in women studying outside the health field.

It was determined that $18.17 \%$ of the participants were studying in science-related departments, while $81.83 \%$ were studying in social-related departments, $66.2 \%$ were equal in income and expenses and $87.7 \%$ had health insurance. It was determined that $96.7 \%$ of the participants had no problem with breast before and that $6.3 \%$ had breast examination in the last year. It was also determined that there was a statistically significant difference between those who had a problem with breast before and those who had breast examination in the last year. Aker et al. (2015) reported that $9.4 \%$ of women had a history of breast mass detection. Ilhan et al. (2014) reported that students who had breast cancer in their families had more BSE than those who did not have breast cancer in their families. The studies are consistent with our results $[4,10]$.

In the study, it was found out that $15.17 \%$ applied BSE and that $14.8 \%$ had breast cancer in their relatives. It was determined that there was a statistically significant relationship between BSE and those who had breast cancer. In Sri-Lanka, $98.6 \%$ of women health workers heard about BSE, but $47.9 \%$ of them applied it every month. In a study conducted in Singapore, it was reported that $93 \%$ of nurses applied BSE [22,23]. In two different studies conducted in Nigeria, it was found that $62.2 \%$ to $95.8 \%$ of 
women health professionals working in a health care institution performed BSE once a month [24,25]. According to the findings of this study, the rate of performing BSE in the studies carried out in female health workers abroad is high.

Kartal et al., (2017) reported that $11.1 \%$ regularly performed breast self-examination every month, and in the study of Sohbet \& Karasu (2017), 26.2\% had a history of breast cancer in their families and $21.5 \%$ had BSE once a month [12,26]. Studies conducted on women who are outside the health sector in Turkey are in line with the study findings. The situation of women performing BSE applications is not at the desired level. However, it was found that $53.3 \%$ of university students studying in healthrelated departments regularly performed BSE and that those who had a family history of breast cancer applied it more [4]. According to the results of this study, the rate of performing BSE is very high. It is thought that awareness should be increased for students outside the health field.

In this study, the most common findings in breast cancer are among the answers given in breast pain, breast swelling, armpit swelling, and bloody discharge in the breast. While the study of Alan, Karadağlı, Şıpkın, \& Kocadaş (2016) stated the mass in the breast, swelling in the auxiliary lymph nodes of the same side, abnormal growth of the breast and asymmetric growth of the breast are specified, Şen and Başar (2012)'s study stated in the breast pain, swelling and breast under the arm and nipple discharge $[27,28]$. The findings of this study are consistent with our results. Common symptoms in breast cancer are very important in early diagnosis.

It was determined that half of the participants received information about BSE. Alan et al. (2016) and Sen and Basar (2012) reported that approximately $62 \%$ of women received information about BSE, while Aker et al. (2015) reported that approximately $80.5 \%$ of women [10,27,28] received information about BSE. In this study, the frequency of having information about BSE was close to the results obtained in other studies in our country, but it is not too high. These findings show that education programs related to BSE should practically be explained especially from the age of 20.

It was determined that $16.7 \%$ of the women who had information about BSE learned this information from health personnel, 9.0\% from TV/radio/newspaper, and 7.3\% from the internet. This finding is consistent with the results of various studies in our country [26,27,28]. It makes us think that it would be beneficial for women to be provided with the right information regularly through mass media and social media.

The difference between the mean scores of sensitivity, obstacle, and health motivation and the confidence subscale scores of the students with and without BSE was statistically significant. There was no statistically significant difference between the benefit and seriousness of subscale mean scores. In the study of Karayurt, Coşkun, and Cerit (2008), the difference between the mean scores of sensitivity, benefit, obstacle, health motivation, and the confidence subscale scores of nurses with and without BSE was statistically significant [29]. There was no statistically significant difference between the mean scores of the seriousness subscale. Aker et al. (2015) stated that there was a statistical difference between the mean scores in the severity/care, barriers, and self-efficacy sub-dimensions [10]. The studies show that health belief is effective in women's BSE practice.

\section{Conclusion and Recommendations}

Early diagnosis methods continue to be important in preventing breast cancer and reducing morbidity and mortality. In order to disseminate early diagnosis behaviours, it is important to first 
determine the factors that are effective for women to perform these behaviours, then to organize training programs and to support these training with reminders. In this study, it was concluded that women who were not in the field of health had insufficient knowledge about breast cancer, BSE, early diagnosis, symptoms, and physician examination. For this reason, awareness about breast cancer and BSE attitudes and beliefs should be raised and sustained for students in science and social departments. Training should be given in a practical and peer education manner. Mass media and social media, especially for women, can be used to deliver the right messages and raise awareness. In collaboration with health professionals and universities, training should be delivered to a wider audience.

\section{Limitations of the Study}

Inability to reach all of the students in the study, incomplete filling of the survey questionnaires, and those who did not volunteer to participate in the study constituted the limitation of the study. The results of the research can be generalized to the universe where the study is conducted.

Acknowledgments: The authors are grateful for the support of all the students who participated in the study.

\section{Ethical Approval}

Permission was obtained from the Ethics Committee of Uşak University (Code of Ethics: 97627247050.99-8887) on March 10, 2016, to conduct the study. Necessary permissions were obtained from the institutions. Before starting the data collection process, the students were informed about the purpose and scope of the research and their verbal and written consents about the fact that they agreed to participate in the research were obtained.

\section{Conflict of interest}

The authors declare that they have no conflict of interest.

The compliance to the Research and Publication Ethics: This study was carried out in accordance with the rules of research and publication ethics.

\section{References}

[1] Cancer Key facts 12 September 2018. WHO. https://www.who.int/en/news-room/factsheets/detail/cancer (accessed Aug 11, 2020)

[2] World Health Organization (WHO), Breast Cancer (2019). https://www.who.int/cancer/prevention/diagnosis-screening/breast-cancer/en/

[3] (accessed Apr 4, 2020)

[4] TÜIKK. Ölüm Nedeni İstatistikleri, 2016. http://tuik.gov.tr/PreTablo.do?alt_id=1083 (accessed Apr $5,2020)$

[5] İlhan, N., Çöl, A.G., Tanboğa, E., et al., "Behavior of college students in health-related departments towards early diagnosis of breast cancer", Journal Breast Health, 10(3), 147-53. 2014. doi: https://doi.org/10.5152/tjbh.2014.2098.

[6] Hadi, M. A., Hassali, M. A., Shafie, A. A., et al., "Evaluation of breast cancer awareness among female university students in Malaysia", Pharmacy Practice, 8(1), 29-34, 2010. doi:10.4321/s1886-36552010000100003. 
[7] Abduelkarem, A. R., Saif, F. K., Saif, S., et al., "Evaluation of breast cancer awareness among female university students in the university of Sharjah, UAE", Advances in Breast Cancer Research, 4(01), 9-21, 2015. doi: 10.4236/abcr.2015.41002.

[8] Breast Cancer Facts \& Figures 2013-2014. American Cancer Society. file:///C:/Users/Dell/Downloads/breast-cancer-facts-and-figures-2013-2014.pdf. (accessed Apr $10,2020)$

[9] Açıgöz, A., Çehreli, R., \& Ellidokuz, H., "Determination of Knowledge and Behavior of Women Working at a Hospital on Breast Cancer Early Detection Methods, and Investigation of Efficiency of Planned Education", Journal of Breast Health, 11(1), 31-8, 2015. doi: 10.5152/tjbh.2014.2322.

[10] Mavi Aydoğdu, S. G., Karapelit, Z., "To determine the knowledge and attitude of midwifery students about breast self-examination”, Androloji Bülteni, 19(3), 78-85, 2017. doi: 10.24898/tandro.2017.39200.

[11] Aker, S., et al., "Practice of Breast Cancer Early Diagnosis Methods among Women Living in Samsun, and Factors Associated with This Practice", Journal Breast Health, 11(3), 115-22, 2015. doi: 10.5152/tjbh.2015.2547.

[12] Karasu, F., Göllüce, A., Güvenç, E., et al., "The effectiveness of training given about breast cancer in a foundation unversity students", Mersin University Journal of Health Science, 10(1), 14-24, 2017.

[13] Kartal, A., İnci, F. H., Koştu, N., et al., "Effect of individual training given to women in the home environment on health beliefs for breast self-examination", Pamukkale Medical Journal, 10(1), 7-13, 2017. doi: 10.5505/ptd.2017.35651.

[14] Kan'an, A., "Evaluation of Breast Cancer (BC) awareness among female university students in Zarqa University, Jordan”, European Journal Of Breast Health, 14(4), 199-204, 2018. doi:10.5152/ejbh.2018.4048.

[15] Champion, V. L., Skinner, C. S., The Health Belief Model, Health behavior and health education: Theory, research, and practice, San Francisco, pp.45-65,2008.

[16] Gençtürk, N., "The Status of knowledge and practıce of early diagnosıs methods for breast cancer by women healthcare professionals", Journal of Breast Health, 9(1), 5-9, 2013.

[17] Akgün ŞZ, Kardaş ÖF., "Assessment of the knowledge, beliefs and attitudes of women living in Kars regarding the practice of breast self-examination", Journal of Medical Research, 13(2), 5461., 2015.

[18] Champion, V.L., "Instrument development for health belief model constructs", Advance in Nursing Science, 6 (3), 73-85,1984. doi: 10.1097/00012272-198404000-00011.

[19] Gözüm, S., Aydın, I., "Validation evidence for Turkish adaptation of Champion's Health Belief Model Scales”, Cancer Nursing, 27(6), 491-8, 2004. doi:10.1097/00002820-200411000-00009. 
[20] Karayurt, O., Dramal, A., “Adaptation of Champion's Health Belief Model Scale for Turkish women and evaluation of the selected variables associated with breast self-examination", Cancer Nursing, 30(1), 69-77, 2007. doi:10.1097/00002820-200701000-00013.

[21] Babuş, S., Eser E., "A Research on the knowledge, attitudes and behaviours towards breast cancer and the methods for early diagnosis in two selected areas of Manisa", Journal of Continuing Medical Education, 26(6), 221-230, 2017.

[22] Kolutek, R., Avc1, İ. A., "The Effect of training and monitoring at home on the knowledge level and practices of married women regarding breast and cervical cancer", Journal of Breast Health, 11(4), 155-62, 2015. doi: 10.5152/tjbh.2015.2647.

[23] Nilaweera, R. I. W., Perera, S., Paranagama, N., et al., "Knowledge and practices on breast and cervical cancer screening methods among female health care workers: a Sri Lankan experience", Asian Pacific Journal of Cancer Prevention, 13(4), 1193-1196, 2012. doi:10.7314/apjcp.2012.13.4.1193.

[24] Chong, P. N., Krishnan, M., Hong, C. Y., et al., "Knowledge and practice of breast cancer screening amongst public health nurses in Singapore", Singapore Medical Journal, 43(10), 509$516,2002$.

[25] Ibrahim, N. A., Odusanya, O. O., "Knowledge of risk factors, beliefs and practices of female healthcare professionals towards breast cancer in a tertiary institution in Lagos, Nigeria", BMC Cancer, 9(1), 76, 2009. doi: 10.1186/1471-2407-9-76.

[26] Akhigbe, A. O., Omuemu, V. O., "Knowledge, attitudes and practice of breast cancer screening among female health workers in a Nigerian urban city”, BMC Cancer, 9(1), 203, 2009. doi: 10.1186/1471-2407-9-203.

[27] Sohbet, R., \& Karasu, F., "Investigation of The Knowledge, Behavior And Applications Of Their Women Towards Breast Cancer", Gümüşhane University Journal of Health Sciences, 6(4), 113 $121,2017$.

[28] Alan, H., Karadağlı, F., Şıpkın, S.,et.al., "Determınıng The Knowledge Attıtude About Breast Cancer And Practıces Of Nursing Students", Haydarpaşa Numune Training and Research Hospital Medical Journal, 56 (1),13-22, 2016.

[29] Şen, S., Başar, F., "Breast Cancer and Breast Self Examination Knowledge Of Women Who Live İn Kütahya Region”, The Journal of Breast Health, 8(4), 185-190, 2012.

[30] Karayurt, Ö. Coşkun, A., \& Cerit, K., 'Nurses’ belıefs about breast cancer and breast self examınation and their breast self examınation performance", Journal of Breast Health, 4(1), 15$20,2008$. 